\title{
Therapeutic Effectiveness over Ground Walking with Body Weight Support Treadmill Training for the Treatment Subacute Stroke Gait Dysfunction
}

\author{
Karthikeyan $\mathrm{T}^{*}$ \\ Physiotherapist, Physiotherapy Center, NIMHANS, Bangalore, Karnataka, India
}

${ }^{\star}$ Corresponding author: Karthikeyan T, Physiotherapist, Physiotherapy Center, NIMHANS, Bangalore, Karnataka, India; Tel: +919448343356; E-mail: karthik_77in@yahoo.co.in

Received: July 04, 2021; Accepted: July 19, 2021; Published: July 21, 2021

\begin{abstract}
Background: Stroke is an acute onset of neurological dysfunction due to abnormality in cerebral circulation with resultant signs and symptoms that correspond to the involvement of focal areas of the brain. Among all the neurological diseases of adult life, the cerebral vascular ones clearly rank first in frequency and importance.
\end{abstract}

Aim: To find out the effectiveness of over ground walking with treadmill gait training in right side subacute stroke subjects.

Settings and design: Physiotherapy Center, NIMHANS, Bangalore. Simple Random Sampling Technique used in this study.

Methods and material: 30 Subjects were selected on the basics of inclusion and exclusion criteria. All the subjects were divided equally into two groups; control Group and experimental Group. Before starting the training, pre-test scores are measured by using cadence and stride length. Control group received over ground walking and experimental group received over ground walking with treadmill gait training for 30 minutes, and both the groups received conventional therapy. At the end of five months, post-test scores of both groups were taken by used measure the cadence and stride length.

Results: Overground gait training with Treadmill gait training group post-test score $(71.3, \mathrm{p}<0.05)$ showed better improvements in mobility and gait speed, When compared to over ground gait training group $(58.2 .3, \mathrm{p}<0.05)$.

Conclusion: The present study which proved that the use of body weight support treadmill training with partial body weight support combined with conventional physiotherapy to be more effective in improving gait ability in subacute subjects.

Keywords: Body weight support, Treadmill gait training, Gait speed, Mobility, Overground gait training

\section{Introduction}

Stroke refers to the sudden death of some brain cells due to a lack of oxygen when the blood flow to the brain is impaired by blockage or rupture of an artery to the brain [1].

Stroke may be manifested as Hemiplegia, which is the paralysis of muscles of one side of the body, contralateral to the side of the brain in which CVA occurred $[2,3]$. Clinically a variety of deficits are possible including the changes in the level of consciousness, impairments of sensory, motor, cognitive, perceptual and language functions. The locations of lesion, the extent of lesion, and the amount of collateral blood flow and early acute care management determine the severity of neurological deficits [4-6].

$28 \%$ of stroke occurs in individuals under the age of 65 years. The incidence of Stroke is about $19 \%$ higher for males than females $[7,8]$.

Stroke can be classified by etiological basis (Ischameic or Haemorrhagic), vascular basis (territory involvement), anatomical basis (cortical or brainstem or capsular or cerebellar or spinal), severity basis (minor or major) progression basis (completed or evolving) and onset basis (infantile or young or elderly stroke).

Stroke usually results in some degree of muscle weakness. It may lead to difficulty with producing force effectively within the context of a task and slowness to produce force is few of the commonest problems faced by the stroke subjects [9]. Moreover several studies have shown that muscle weakness is associated with reduced walking speed and endurance. And also muscle weakness has been suggested as a significant predictor of walking ability in stroke subjects [10].

\section{Statement of Problem}

Study on analyzing the effectiveness of Treadmill training with partial body weight support and physiotherapy in improving gait ability after stroke.

\section{Need for the Study}

Locomotion is one of the commonest problems after stroke in terms of asymmetry and reduction of speed etc. The most often stated goal for stroke subjects is to improve walking. For the improvement of walking, 
good strength of the lower extremity muscles is essential irrespective of the presence of spasticity because of growing evidence that muscle weakness rather abnormal reflex activity is a major limiting factor in physical function particularly for locomotor tasks following stroke. Through this study I would like to find out the effectiveness of body weight support treadmill training with partial body weight support and physiotherapy in improving gait ability of stroke subjects

\section{Objectives}

1. To determine the effect if body weight support treadmill training with partial body weight support and physiotherapy in improving gait ability of stroke subjects in group A subjects.

2. To determine the effect of body weight support treadmill training alone in improving gait ability of stroke subjects in group B.

3. To determine the difference between the effectiveness of body weight support treadmill training with partial body weight support and physiotherapy in improving gait ability of stroke subjects.

\section{Materials Used in This Study}

$\begin{array}{ll}\text { 1. } & \text { Treadmill } \\ \text { 2. } & \text { Supporting Harness } \\ \text { 3. } & \text { Set of pulleys } \\ \text { 4. } & \text { Couch } \\ \text { 5. } & \text { Pillows } \\ \text { 6. } & \text { Towels } \\ \text { 7. } & \text { Sand Bags } \\ \text { 8. } & \text { Swiss Ball } \\ \text { 9. } & \text { Parallel Bar }\end{array}$

\section{Methodology}

\section{Research Design}

The design that is used for this study is experimental study design

\section{Study Setting}

Physiotherapy Center NIMHANS Bangalore

\section{Study Sample}

A total Number of 30 patient with stroke were selected by random sampling method with consideration of inclusion criteria and exclusion criteria and they were divided in to Group A and Group B.

\section{Study Duration}

All subjects participated in comprehensive 6 months Rehabilitation program.

A three week baseline study consisted of occupation therapy, and speech and neuro physiological therapy according to individual needs. During the subsequent 3 weeks of specific intervention gait training measured. Group A-Body weight support treadmill training with partial body weight support for 30 minutes 5 times a week. Group B - Body weight support treadmill training with partial body weight support for 30 minutes 5 times a week for 3 weeks.

Experimental Group (Group A): It consists of 15 subjects who underwent body weight support treadmill training and physiotherapy

Control Group (Group B): It consists of 15 subjects who underwent only partial body weight supported treadmill training.

\section{Criteria for Selection}

Inclusion Criteria: Subjects with all types of stroke.

1. Age group between 29-40 years.

2. Subjects of willingness of participate in the study.

3. Subjects with both right and left hemiplegia

4. Both genders.

5. Able to understand at least simple instructions.

6. No other orthopedic or neurological diseases impairing mobility.

\section{Exclusion Criteria}

1. Subjects with other musculoskeletal disorder.

2. Medically unstable.

3. Non Co-operative subjects.

\section{Parameter Used}

Functional ambulation category (FAC).

\section{Interventions}

The purpose of the treatment and aim of the study were explained subjects who are selected for the treatment. All patients signed the consent form before undergoing treatment program. Subjects in group A was treated with body weight support treadmill training with partial body weight support and conventional physiotherapy. Subjects in group B was treated with exclusive body weight support treadmill training with partial body weight support. The treatment was given for both groups for periods of 6 months.

\section{Procedure}

Subjects were supported in a modified parachute harness suspended centrally by a set of pulleys connected to a flexible spring.

At the beginning of the therapy, two therapists provided manual help to correct gait deviations. One therapist sitting by the paretic side facilitated the swing of the paretic limb, determined that its initial ground contact was made with the heel, and prevented knee hyperextension during mid stance and encouraged symmetry of step length and stance symmetry.

The second therapist stood on the treadmill behind the patient and facilitated weight-shift onto the stance limb, hip extension and trunk erection. Mean treadmill speed was 0.21 (range $0.15-0.30 \mathrm{~m} / \mathrm{s}$ was reached 
Karthikeyan T (2021) Therapeutic Effectiveness over Ground Walking with Body Weight Support Treadmill Training for the Treatment Subacute Stroke Gait Dysfunction

and kept constant until the end. The mean BWS was 27\% (range 20-30) of body weight at the beginning. The support whilst 10 subjects needed a support of 5-15\% BWS until the end. Net walking a support of treadmill was approximately $20 \mathrm{~min}$ per session with a brief rest in the middle.

\section{Results}

The pre and post-test values were assessed for gait ability in Group A. the standard deviation was 0.4 . The ' $\mathrm{t}$ ' values were calculated for gait ability by paired ' $\mathrm{t}$ ' test was 28.5 and it was more than table value 2.15 for $5 \%$ level of significant at 14 degrees of freedom (Figures 1, 2, Tables 1 and 2).

\section{Mean Difference Group A \& B}

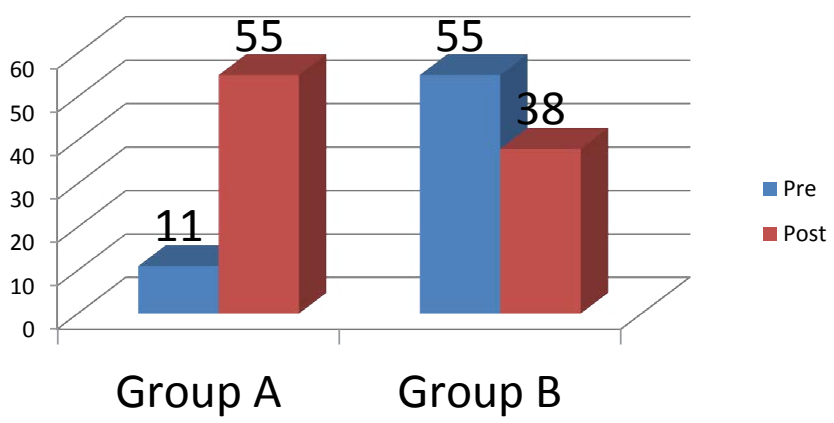

Figure 1: Mean and mean difference value for group A and group B.

\section{SD Between Group A \& B}

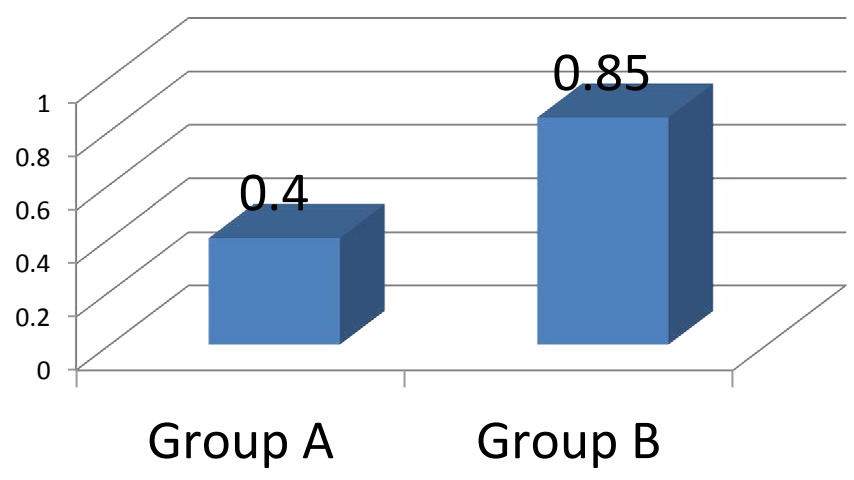

Figure 2: Standard Deviation value for Group A and Group B.

Table 1: Mean and mean difference value for group A and group B.

\begin{tabular}{|l|c|c|c|}
\hline \multirow{2}{*}{ Study Group } & \multicolumn{3}{|c|}{ Walking Ability } \\
\cline { 2 - 4 } & \multicolumn{2}{|c|}{ Mean } & Mean Difference \\
\hline \multirow{2}{*}{ Group A } & Pre & Post & 3 \\
\cline { 2 - 4 } & 11 & 55 & 1 \\
\hline Group B & 25 & 38 & \multicolumn{2}{|c|}{} \\
\hline
\end{tabular}

Table 2: Standard Deviation value for Group A and Group B.

\begin{tabular}{|l|c|}
\hline \multirow{2}{*}{ Study Group } & Standard Deviation \\
\cline { 2 - 2 } & Walking Ability \\
\hline Group A & 0.4 \\
\hline Group B & 0.85 \\
\hline
\end{tabular}

The pre and post-test values were assessed for gait ability in Group B. the standard deviation was 0.85 . The ' $t$ ' vales were calculated for gait ability by paired ' $\mathrm{t}$ ' test was 4.5 and it was more than table value 2.15 for $5 \%$ level of significance at 14 degrees of freedom (Figure 3 and Table 3 ).

The calculated ' $t$ ' values by unpaired ' $t$ ' test was 8.5 . The calculated' values were more than the table value 2.05 for $5 \%$ level of significance of 28 degrees of freedom (Figure 4 and Table 4).

The paired ' $t$ ' values have shown that body weight support treadmill training with partial body weight support combined with physiotherapy are more effective for the improving gait ability of subjects after stroke. The unpaired ' $\mathrm{t}$ ' test values have shown that there is significant difference in showing improvement in gait ability of stroke subjects.

\section{Difference between Paired t \& t value}

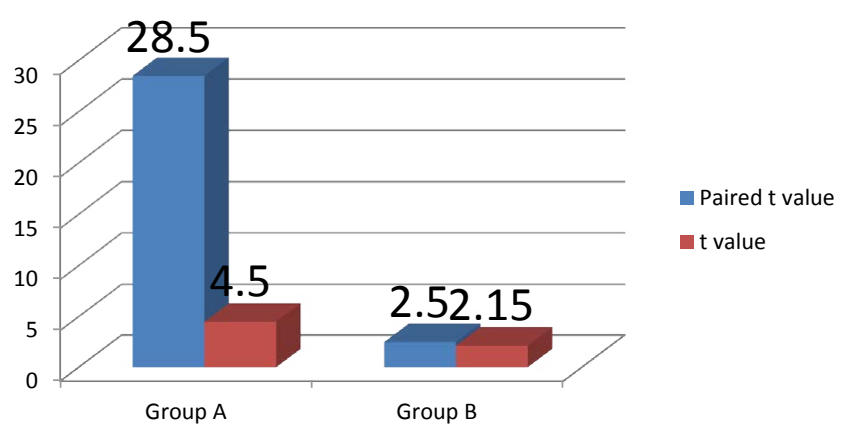

Figure 3: Paired ' $t$ ' test values for Group A and Group B.

Table 3: Paired ' $\mathrm{t}$ ' test values for Group A and Group B.

\begin{tabular}{|l|c|c|c|}
\hline \multirow{2}{*}{$\begin{array}{l}\text { Study } \\
\text { Group }\end{array}$} & Calculated Paired 't' Values & \multirow{2}{*}{ Table Value } & Significance \\
\cline { 2 - 3 } & Walking Ability & & \\
\hline Group A & 28.5 & 2.15 & Significant \\
\hline Group B & 4.5 & 2.15 & Significant \\
\hline
\end{tabular}

\section{Difference between $\mathrm{t} \&$ Table value}

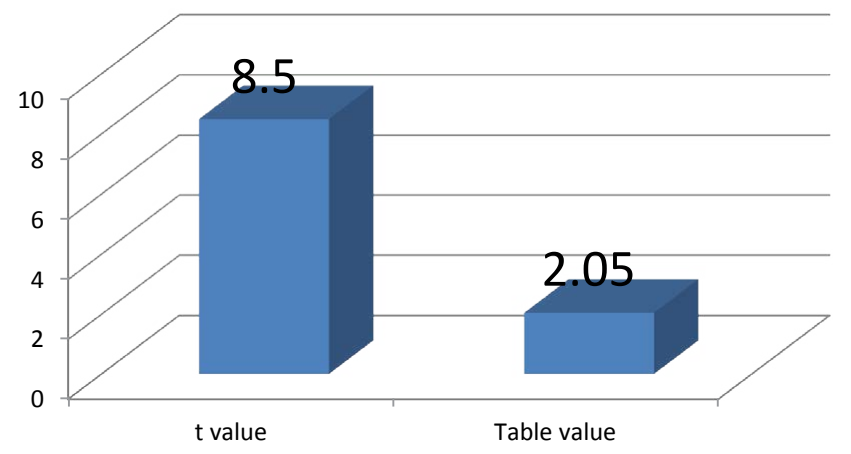

Figure 4: Un paired ' $\mathrm{t}$ ' test Values for walking ability in Group A and B.

Table 4: Un paired ' $\mathrm{t}$ ' test Values for walking ability in Group A and Group B.

\begin{tabular}{|l|c|c|c|}
\hline \multirow{2}{*}{ Study Group } & Calculated Unpaired 't' Values & Table Value & Significant \\
\cline { 2 - 3 } & Walking Pattern & Significant \\
\hline $\begin{array}{l}\text { Comparison of Group A } \\
\text { and Group B }\end{array}$ & 8.5 & 2.05 & Sin \\
\hline
\end{tabular}


This study has proved the 3 week combination of body weight support treadmill training with BWS and physiotherapy effected a large improvement of a gait ability of non-ambulatory hemi paretic subjects than an exclusive 3- week treadmill therapy with BWS.

\section{Discussion}

This study has proved that The 3 week combination of body weight support treadmill training with conventional physiotherapy effected a large improvement of a gait ability of non-ambulatory hemi paretic subjects than an exclusive 3- week treadmill therapy with BWS.

Recently, Kwakkel et al. reported that greater intensity of leg rehabilitation improved gait ability and activities of daily living in acute stroke victims [11]. The key elements of their lower limb rehabilitation program were comparable with the physiotherapy within the present study.

Richards et al had shown that an additionally applied, task-specific program including body weight support treadmill training without body weight support resulted In a larger gait velocity in acute stroke victims 6 weeks after study onset as compared with a conventionally treated group who received less therapy $[12,13]$.

The potential for motor recovery after stroke therefore seems to be limited, and subjects of group A probably reached this presumed level faster, i.e. the combined treatment of physiotherapy and body weight support treadmill training accelerated motor recovery $[14,15]$. Richards et al. also reported in the above mentioned study that differences in gait ability between the high and low-intensity group had waned at follow-up 6 months later, also because of a further improvement of a large extent in the low- intensity group.

\section{Conclusion}

From the results of this study 3 weeks of body weight support treadmill training with BWS pulls physiotherapy accelerated the restoration of gait ability in chronic hemi paretic subjects; correspondingly, a focused and intense treatment regime including locomotion training seems most promising in gait rehabilitation after stroke.

The result was analyzed using which proved that the use of body weight support treadmill training with partial body weight support combined with physiotherapy to be more effective in improving gait ability in hemi paretic subjects.

\section{Limitation of the Study}

1. This Study has been conducted on small size sample only.

2. The outcome of the study has been limited to improving gait ability only.

\section{Recommendations}

1. Further study may be extended with large sample.
2. Other aspect of motor impairment such as balance, strength may be considered.

3. The patient ability to either improve or retain the regained functional capacity may be assessed at regular intervals over a period of time.

4. The efficacy of this treatment may be found by altering the frequency and intensity.

5. The extended efficacy of these exercises may also be found out by increasing the total in duration of the treatment.

The body weight support treadmill training with partial body weight support may be applied to other neurological conditions such as Paraplegia.

\section{References}

1. Asanuma H, Keller A (1991) Neurobiological basis of motor learning and memory. Concepts Neuro Sci 2: 1-30.

2. Carr J, Shepherd R (1998) Neurological Rehabilitation. Butterworth \& Heinemann, Oxford.

3. Collen FM, Wade DT, Bradshaw CM (1990) Mobility after stroke: reliability of measures of impairment and disability.

4. Dietz V, Colombo G Jensen L, Baumgartner L (1995) Locomotor capacity of spinal cord in paraplegic subjects. Ann Neurol 37: 574-582.

5. Grilner S (1985) Neurologic basis of rhythmic motor acts in vertebrates. Science 228 143-149.

6. Hesse S, Berlet C, Schaffrin A, Malezic M, Mauritz KH (1994) Restoration of gait in non- ambulatory hemiparetic subjects by treadmill with partial body weight support. Arch Med Rehabil 75: 1087-1093.

7. Hesse S, Bertelt C, Jahnke MT, et al. (1995) Body weight support treadmill training with partial body weight support as compared to physiotherapy in non-ambulatory heparetic subjects. Stroke 26: 976-981.

8. Hesse S, Malezic M, Schaffrin A, Maurtiz KH (1995b) Restporation of gait by a combained body weight support treadmill training and multichannel electrical stimulation in non-ambulatory hemiparetic subjects. Scand J Rehabil Med 27: 199205.

9. Holden MK, Gill KM, Magliozzi MR (1986) Gait assessment for neurologically impaired subjects.Standards for outcome assessment. Phys Ther 66: 1530-1539.

10. Jorgensen HS, Nakayama H, Raaschou HO, Olsen TS (1995) Recovery of walking function in stroke subjects:the Copenhagen stroke study. Arch Phys Med Rehabil 76: 27-32.

11. Kwakkel G, Wagenaar RC, Twisk JWR, Lankhorst GL, Koetsier JC (1999) Intensity of leg and arm training after middle cerebral artery stroke:a randomized trail. Lancent 354: 191-196.

12. Visintin M, Barbeau H, Korner-Bitensky N, Mayo NE (1998) Anew approach to retain gait in stroke subjects through body weight support and treadmill stimulation. Stroke 29: 1122-1128.

13. Werning A, Muller S (1992) Laufband locomotion with body weight support in persons with severe spinal cord injuries. Paraplegia 30: 229-238.

14. Lovely RG, Gregor RJ, Roy RR, Edgerton VR (1986) Effects of training on the recovery of full weight bearing stepping in the adult spainal cat. Exp Neurol 92: 421-435.

15. Visintin M, Barbeau H (1989) The effects of body weight support on the locomotor pattern of spastic paretic subjects. Can J Neurol Sci 16: 315-325.

\section{Citation:}

Karthikeyan T (2021) Therapeutic Effectiveness over Ground Walking with Body Weight Support Treadmill Training for the Treatment Subacute Stroke Gait Dysfunction. Internal Med Res Open J Volume 6(3): 1-4. 